\title{
Moist air in the treatment of laryngotracheitis
}

Acute viral laryngotracheitis (croup) is the most common cause of acute laryngeal obstruction in childhood. Inhalation of warm moist air is treatment widely recommended in the belief that it eases discomfort and helps prevent inflamed laryngeal mucosa becoming dry and crusted. Owing to the risk of burns from steam kettles, moist atmospheres are now produced in hospitals by devices which blow out water droplets of various sizes suspended in a driving gas, usually oxygen. The actual water content of the mixture varies according to the machine and because droplets of water suspended in air are unstable they either coalesce and fall as rain, or condense on the surrounding surfaces, or evaporate into the atmosphere. Thus the mixture the child inhales varies and depends on the proximity of the machine. If he inhales close to the jet he may have a high water intake and become overhydrated. ${ }^{12}$ On the other hand, if the mist has cleared and the atmosphere has been cooled because the jet is too distant, the infant may actually inhale less moisture than if he were to inhale air enriched by gas that his mother has just exhaled.

If we assume that cold mists are used in such a way that water enriched gases reach the airway, is there any evidence that they relieve symptoms, reduce obstruction, or alter the course of the illness? We could not find any ${ }^{3}$ and this leaves us to make a clinical judgement.

Placing a child in a warm moist atmosphere seems a reasonable and, at the very least, a harmless step. At home this is quickly achieved by running hot water in the bathroom. Within half an hour or so parents embracing their infants often observe an improvement in symptoms. Whether this is due to the warmth, the moisture, or the comfort, or a mixture of all three is a matter for speculation. Certainly comfort and reassurance are essential components.

When the degree of airways obstruction is severe enough to demand admission to hospital, the most important aspects of management appear to be careful confident nursing and minimal disturbance necessary to observe the child adequately. Reassuring the parent is often the best way to reassure the child. If the child is nursed in a warm area with reasonable relative humidity there seems little justification for additional particulate water vapour. It is hard to imagine anything more distressing to a frightened young child who has just been admitted to hospital than sitting in a cold fog separated from his parents by an enclosing plastic tent and finding it difficult to see them because of the water and mist. Anxiety may cause the child to hyperventilate, which will worsen airways obstruction and increase oxygen demand. It seems unreasonable to submit children to such a procedure until we have evidence that it is beneficial.

Cold dry air contributes to exercise induced asthma and should be avoided. If dry piped gases such as oxygen are required they must be warmed and humidified. It does not follow, however, that all inspired air needs to be fully water saturated and at body temperature.

Whether humidification of inhaled gases is helpful in the management of viral croup remains an unresolved question. Nevertheless, we wonder whether future generations will regard the present approach of putting children in mist filled plastic envelopes in much the same way that we now view the past use of leeches in medicine. The evidence needed to resolve this issue will be hard to obtain since a double blind controlled trial seems impossible.

\section{References}

1 Rosenfeld WN, Linshaw M, Fox HA. Water intoxication: a complication of nebulization with nasal CPAP. J Pediatr $1976 ; 89$ : $113-4$.

2 Tamer MA, Modell JH, Rieffel CN. Hyponatremia secondary to ultrasonic aerosol therapy in the newborn infant. J Pediatr 1970; 77: 1051-4.

3 Phelan PD, Landau LI, Olinsky A. Respiratory illness in children, second edition. Oxford: Blackwell Scientific Publications, 1982: 108.

RICHARD HENRY University Hospital, Queen's Medical Centre, Nottingham NG7 $2 \mathrm{UH}$ 